\title{
CRITÉRIOS MORFOLÓGICOS E TAXONÔMICOS DE LATOSSOLO E NITOSSOLO VALIDADOS POR PROPRIEDADES FÍSICAS MENSURÁVEIS ANALISADAS EM PARTE PELA GEOESTATÍSTICA ${ }^{(1)}$
}

\author{
Célia Regina Grego ${ }^{(2)}$, Ricardo Marques Coelho ${ }^{(3)} \&$ Sidney Rosa Vieira ${ }^{(4)}$
}

\begin{abstract}
RESUMO
A morfologia e a classificação do solo estabelecem referenciais em atributos do solo que podem ser usados para inferência de propriedades ou para correlacionar sistemas e resultados de manejo entre sítios sob mesmas condições. Apesar das evidências nesse sentido, atributos morfológicos ainda são criticados por sua subjetividade. $\mathrm{O}$ objetivo deste estudo foi validar o uso de atributos morfológicos do solo, usados na taxonomia, como preditores de propriedades físicas mensuráveis e analisadas pela geoestatística, particularmente aquelas que diferenciam horizontes $B$ níticos de B latossólicos. Três perfis de solo selecionados em áreas manejadas com sistema de plantio direto e em preparo convencional sob pousio foram descritos morfologicamente e classificados. Os perfis estudados foram classificados como Latossolo Vermelho distroférrico típico, tanto no sistema de plantio direto (LD) como no cultivo convencional (LC), e como Nitossolo Vermelho distroférrico latossólico (ND), todos de textura muito argilosa. Amostras foram coletadas por horizonte genético, para caracterização físico-hídrica (curva de retenção de água, porosidade e densidade do solo), química e granulométrica. Em uma das paredes do perfil $(0,40 \times 1,5 \mathrm{~m})$, em uma grade de 80 pontos distanciados de $10 \mathrm{~cm}$, foram realizadas medições de resistência do solo à infiltração de água e de resistência do solo à penetração, para análise de dependência espacial utilizando geoestatística. A estrutura menos desenvolvida e a menor espessura do horizonte A do solo sob plantio convencional refletiram o revolvimento excessivo e a eliminação da cobertura do solo. O Nitossolo Vermelho distroférrico latossólico
\end{abstract}

\footnotetext{
(1) Recebido para publicação em outubro de 2009 e aprovado em janeiro de 2011.

(2) Pesquisadora da Embrapa Monitoramento por Satélite. Av. Soldado Passarinho 303, Jardim Chapadão, CEP 13070-115 Campinas (SP). E-mail: crgrego@cnpm.embrapa.br

${ }^{(3)}$ Pesquisador Científico do Instituto Agronômico de Campinas, Centro de P\&D de Solos e Recursos Ambientais. Caixa postal 28, CEP 13001-970 Campinas (SP). E-mail: rmcoelho@iac.sp.gov.br

(4) Pesquisador Científico do Instituto Agronômico de Campinas, Centro de P\&D de Solos e Recursos Ambientais. Caixa postal 28, CEP 13001-970 Campinas (SP). E-mail: sidney@iac.sp.gov.br
} 
diferiu dos demais por apresentar estrutura forte e em blocos desde a superfície até a profundidade de $1,0 \mathrm{~m}$, caracterizando, em associação com sua cerosidade, horizonte B nítico sobrejacente a B latossólico. A estrutura do horizonte nítico condicionou não apenas a classificação do solo, mas também a resistência do solo à penetração e à infiltração de água e a retenção de água do solo. Os limites verticais dos horizontes diagnósticos de superfície e subsuperfície definidos por critérios morfológicos, como estrutura e consistência, mostraram estreita associação com as propriedades físicas mensuradas em campo e analisadas geoestatisticamente, validando os critérios morfológicos na separação de camadas de solo com propriedades físicas diferenciadas. A mensuração das propriedades físico-hídricas dos solos discriminou os horizontes diagnósticos B latossólicos do B nítico, mostrando a validade dos critérios morfológicos e taxonômicos para discriminação desses horizontes diagnósticos nos solos estudados e consolidando o uso desses critérios como indicadores de propriedades físicas diferenciadas dos solos.

Termos de indexação: B latossólico, horizonte B nítico, morfologia do solo, física do solo, variabilidade espacial.

\title{
SUMMARY: MORPHOLOGICAL AND TAXONOMIC CRITERIA OF OXIC AND NITIC HORIZONS VALIDATED BY MEASURABLE PHYSICAL PROPERTIES PARTIALLY ANALYZED BY GEOSTATISTICS
}

\begin{abstract}
Despite evidences that soil morphology and classification can be used to infer measurable soil properties and to correlate management results among different agricultural sites, there is still the need of data to support many of those inferences. The aim of this research was to validate the use of soil morphology and taxonomy to predict soil properties based on measurements and analyzed by geostatistics, mainly those related to Nitic and Ferralic/Oxic soil horizons. Three selected soil profiles under no-tillage and fallow after conventional tillage were described and classified with the Brazilian Soil Classification System. Soils were classified as "Latossolo Vermelho distroférrico típico" (Haplic Ferralsol, Rhodic Hapludox) under notill (LD) and conventional till (LC), and "Nitossolo Vermelho distroférrico latossólico" (Ferralic Nitisol, Rhodic Hapludox) at the no-till site (ND), all with very clayey texture. Samples were collected for soil water retention, particle-size distribution and chemical characterization. In a grid $(0.4 \times 1.5 \mathrm{~m})$ on one of the pit walls measurements of soil resistance to infiltration and penetration were taken at 80 points spaced $10 \mathrm{~cm}$ apart and spatial dependence was analyzed by geostatistics. Conventional tillage practices resulted in a less developed structure and a thinner soil surface A horizon. The "Nitossolo"(ND) differed from the other two pedons with a strong blocky structure and shiny peds down to $1.0 \mathrm{~m}$, characterizing a Nitic B horizon overlying a Ferralic (or Oxic) B horizon. The structure of the Nitic horizon determined not only the soil classification, but also soil resistance to water infiltration and penetration and soil water retention. The vertical limits between surface and subsurface soil horizons defined by field morphology were closely associated to field-measured and geostatistically-analyzed soil physical properties. The Nitic and Oxic/Ferralic diagnostic horizons could be differentiated by measurements of soil physical-hydric properties, indicating these taxonomic criteria as useful for the discrimination of these horizons and confirming their use as indicators of differentiated soil physical properties.
\end{abstract}

Index terms: Ferralic horizon, nitic horizon, soil morphology, soil physical properties, soil spatial variability.

\section{INTRODUÇÃO}

A morfologia e a gênese são a base da taxonomia de solos, tanto em sistemas de abrangência geográfica mundial, a exemplo do Soil Taxonomy - SoilTax (Soil Survey Staff, 1999), quanto em sistemas estritamente nacionais, a exemplo do Sistema Brasileiro de Classificação de Solos - SiBCS (Santos et al., 2006). A morfologia e a classificação também podem ser utilizadas em estudos de manejo e de variabilidade de solos, para estabelecimento de referenciais de condição atual ou para correlacionar sistemas e resultados de manejo entre sítios sob mesmas condições. 
Espera-se que propriedades físicas quantificáveis do solo - a exemplo da condutividade hidráulica, da curva de retenção de água e da resistência à penetração - guardem estreita associação com atributos morfológicos, como estrutura e consistência, embora estes últimos sejam predominantemente qualitativos. De fato, há diversos relatos de atributos morfológicos, como estrutura, consistência e transição entre horizontes, que refletem propriedades físicas quantitativas dos solos, como densidade, resistência à penetração e taxa de infiltração (Jorge \& Prado, 1988; Silva \& Ribeiro, 1997; Lima et al., 2004; Cooper \& Vidal Torrado, 2005).

A variabilidade espacial das propriedades dos solos pode ocorrer tanto horizontal quanto verticalmente, em decorrência de sua origem, localização, tipo ou manejo. Analisando valores de umidade e infiltração de água no solo sob plantio direto na área do presente estudo, Grego et al. (2004) verificaram que os solos da parte inferior da vertente sempre apresentam maiores valores de umidade e de infiltração, estando as diferenças estritamente relacionadas às cotas topográficas e à estrutura do solo. Nesse mesmo sentido, Souza et al. (2006) mostram que, em Latossolos, em áreas de formas côncavas e convexas, independentemente do histórico de manejo, há mais variabilidade de propriedades químicas e físicas do que em áreas de formas lineares. É bem conhecida também a variabilidade dos aspectos agronômicos associados a essa variabilidade das formas da paisagem (Marques Jr. et al., 2008).

Assim, para a adequada caracterização das propriedades do solo, é importante considerar sua variabilidade espacial. A análise geoestatística, método descrito por vários autores que estudaram as propriedades dos solos (Isaaks \& Srivastava, 1989; Goovaertz, 1997; Vieira et al., 2008), é uma ferramenta adequada e fundamental para a análise de propriedades que variem de um local para outro com algum grau de organização ou continuidade, expresso por meio da dependência espacial (Vieira, 2000).

Todavia, a quantificação das propriedades do solo ou do relevo sistematicamente em cada paisagem em caráter rotineiro é inviável por questões de tempo e custo dos trabalhos de campo e de laboratório. Isso torna os métodos dedutivos de estudo da variabilidade do solo, como o levantamento pedológico e os sistemas taxonômicos responsáveis pela sua funcionalidade, bastante atrativos. Assim, é importante a compreensão do relacionamento entre atributos taxonômicos de caráter estritamente diagnóstico, a exemplo dos morfológicos, e dados quantificados e que influenciam os aspectos agronômicos.

O objetivo deste estudo foi validar o uso de atributos morfológicos do solo, usados na taxonomia, como preditores de propriedades físicas mensuráveis e analisadas pela geoestatística, particularmente aquelas que diferenciam horizontes B níticos de B latossólicos.

\section{MATERIAL E MÉTODOS}

\section{Morfologia e amostragem do solo}

Foram abertas três trincheiras de 1,0 x 2,0 x 2,0 m (largura x comprimento $\mathrm{x}$ profundidade) no Centro Experimental de Campinas, SP, no Instituto Agronômico, coordenadas UTM $7.470 .661 \mathrm{~m} \mathrm{~N}$ e $286.832 \mathrm{~m}$ E, em relação ao meridiano 23 - local com clima classificado por Köppen como Cwa e com relevo ondulado. Os solos desenvolveram-se da alteração de rochas intrusivas básicas (diabásio) do grupo São Bento.

Dois perfis (LD e ND) foram selecionados em áreas manejadas com sistema de plantio direto por 18 anos, cultivado com triticale após soja, e um terceiro perfil (LC), em área com preparo convencional sob pousio de três meses após cultivo de soja (LC). Os perfis LD e LC encontram-se posicionados na meia encosta, que apresenta curvaturas em planta e perfil retilíneas; o perfil ND encontra-se em posição de terço inferior, onde a curvatura em planta é retilínea e em perfil, côncava. A descrição morfológica dos perfis foi elaborada de acordo com Lemos \& Santos (1996); como ela faz parte do objetivo do trabalho, todos os detalhes da descrição estão apresentados como resultados.

Amostras de solo foram coletadas por horizonte genético, para realização de análises físicas e químicas do solo. Os solos foram classificados no Sistema Brasileiro de Classificação de Solos, conforme Santos et al. (2006).

\section{Determinações analíticas}

Em uma das paredes do perfil foi estabelecida uma grade de $0,40 \mathrm{~m}$ de largura e $1,5 \mathrm{~m}$ de profundidade. Foram medidos 80 pontos, distanciados de $0,10 \mathrm{~m}$, de resistência do solo à infiltração de água, com um aparelho tipo seringa fabricado pela FHK Kiya Seisakusho, e de resistência do solo à penetração, com um penetrômetro de bolso sem ponta, modelo Solotest.

As amostras indeformadas de solo foram coletadas em anéis de $100 \mathrm{~cm}^{3}$, com três repetições por horizonte genético, para determinação de água nas tensões de $0,0,5,2,6,10,30,100$ e $1.500 \mathrm{kPa}$; e da densidade do solo; macro e microporosidade e porosidade total, por métodos descritos em Klute (1986). Os valores de retenção de água foram ajustados pelo modelo de van Genuchten (1980) para elaboração da curva característica da água do solo. Foram coletadas amostras de solo deformadas para determinação de granulometria pelo método do densímetro (argila, silte, areia grossa e areia fina), conforme descrito em Camargo et al. (1986).

As determinações de $\mathrm{pH}$ em $\mathrm{H}_{2} \mathrm{O}, \mathrm{KCl}$ e $\mathrm{CaCl}_{2}, \mathrm{C}$ orgânico, $\mathrm{P}, \mathrm{K}^{+}, \mathrm{Ca}^{2+}, \mathrm{Mg}^{2+}, \mathrm{Al}^{3+}, \mathrm{H}+\mathrm{Al}, \mathrm{SiO}_{2}, \mathrm{Al}_{2} \mathrm{O}_{3}$, $\mathrm{Fe}_{2} \mathrm{O}_{3}, \mathrm{TiO}_{2}$ e $\mathrm{MnO}$ foram feitas de acordo com Camargo et al. (1986), com cálculo dos valores T, V, m, Ki e Kr. 


\section{Análise geoestatística}

Os dados de resistência do solo à infiltração de água e resistência à penetração foram obtidos em pontos com coordenadas conhecidas nos perfis dos solos, razão pela qual foi possível e adequada a realização da análise geoestatística desses dados. Inicialmente, foram calculados média, desvio-padrão, coeficiente de variação, valor mínimo, valor máximo, assimetria e curtose, para análise exploratória dos dados. Para verificar a dependência espacial, interpolar dados e construir mapas, foi empregada a análise geoestatística, segundo Vieira (2000). Foram construídos semivariogramas, partindo das pressuposições de estacionariedade da hipótese intrínseca e do cálculo da semivariância $\chi($ h) estimada na equação 1:

$$
\gamma(\mathrm{h})=\frac{1}{2 N(h)} \sum_{i=1}^{N}\left[Z\left(x_{i}\right)-Z\left(x_{i}+h\right)\right]^{2}
$$

em que $N(h)$ é o número de pares dos valores medidos $\mathrm{Z}\left(\mathrm{x}_{\mathrm{i}}\right), \mathrm{Z}\left(\mathrm{x}_{\mathrm{i}}+\mathrm{h}\right)$, separados por um vetor $\mathrm{h}$.

Os semivariogramas que apresentaram dependência espacial foram ajustados a um modelo onde foram definidos os parâmetros do semivariograma: $\mathrm{C}_{0}=$ efeito pepita, que é o valor de $\gamma(\mathrm{h})$ quando $\mathrm{h}=0 ; \mathrm{a}=$ alcance, que é a distância em que $\gamma(\mathrm{h})$ permanece aproximadamente constante após aumentar com o aumento de $\mathrm{h} ; \mathrm{C}_{0}+\mathrm{C}_{1}=$ patamar, que é o valor de $\gamma(\mathrm{h})$ a partir do alcance e que se aproxima da variância dos dados; e $\mathrm{C}_{1}=$ variância estrutural, ou seja, a diferença entre o patamar e o efeito pepita. Segundo Vieira et al. (2008), os modelos ajustados para dados da ciência da natureza são na maioria esféricos, porém, em menores frequências, podem ser ajustados o exponencial e o gaussiano; para fenômenos com periodicidade, predomina o modelo hole effect.

Foi calculado o grau de dependência espacial (GD), equação 2, que, de acordo com Zimback (2001), apresenta a seguinte proporção: (a) dependência fraca até $25 \%$; (b) dependência moderada para resultados maiores do que 25 até $75 \%$; e (c) dependência forte para resultados maiores do que $75 \%$.

$$
G D=\left(\frac{C_{1}}{C_{0}+C_{1}}\right) \cdot 100
$$

Observada a existência de dependência espacial definida pelo semivariograma, os valores vizinhos semelhantes possibilitarão estimar valores para qualquer local onde a variável não foi medida usandose a krigagem, segundo Vieira et al. (2000), a qual estima valores com as condições de estimativa sem tendenciosidade e com desvios mínimos em relação aos valores conhecidos, ou seja, com variância mínima. O programa desenvolvido por Vieira et al. (2002) interpola por krigagem valores no espaço amostrado para qualquer posição. Com os valores estimados por krigagem, foram construídos mapas de isolinhas em função da coordenada geográfica, no programa Surfer 7.0 (Golden Software, 1999).

\section{RESULTADOS E DISCUSSÃO}

\section{Classificação e morfologia do solo}

O perfil de solo sob plantio direto (LD) foi descrito e classificado como Latossolo Vermelho distroférrico típico textura muito argilosa, A proeminente, mesodistrófico, caulinítico-oxídico, reação neutra, e situa-se em posição de terço superior a topo de elevação, na altitude de $640 \mathrm{~m}$. Na mesma situação de manejo, o perfil ND foi descrito e classificado como Nitossolo Vermelho distroférrico latossólico, textura muito argilosa, A moderado, mesodistrófico, cauliníticooxídico, reação neutra. O perfil ND situa-se no terço inferior a sopé de vertente, na altitude de $625 \mathrm{~m}$. O solo manejado em preparo convencional, LC, foi classificado como Latossolo Vermelho distroférrico típico, textura muito argilosa, A moderado, mesodistrófico, caulinítico-oxídico, reação neutra. $\mathrm{O}$ perfil LC está situado no terço superior de vertente, na altitude de $633 \mathrm{~m}$.

Os atributos morfológicos dos solos são apresentados no quadro 1. Os dois Latossolos apresentaram horizontes de subsuperfície (B latossólico) equivalentes em espessura e morfologia e diferenciaram-se do horizonte de subsuperfície do ND, B nítico, pela morfologia. O solo ND apresentou estrutura forte média e grande em blocos, de 0 a $0,98 \mathrm{~m}$ de profundidade, contrastando com os dois Latossolos, de estrutura forte granular em todo o perfil, determinante da classificação do horizonte $\mathrm{B}$ diagnóstico desses solos (Santos et al., 2006). A espessura do horizonte superficial dos solos sob plantio direto (LD e ND) foi maior que no solo sob plantio convencional (LC). No sistema de plantio direto, com a não movimentação do solo e a cobertura vegetal mantida na superfície, tende a haver maior acúmulo de matéria orgânica nas camadas superficiais (Cruz et al., 2003), o que explica a maior espessura desses horizontes A sob plantio direto.

O Nitossolo estudado apresenta sequência de horizontes Ap, Bt e Bw. Por apresentar horizonte B latossólico abaixo de B nítico (abaixo de 0,98 m), este foi classificado como Nitossolo com caráter transicional latossólico (Quadro 1). Sua estrutura em blocos com grau de desenvolvimento forte da superfície até o topo do B latossólico (Bw) em posição não diagnóstica, $0,98 \mathrm{~m}$, é fundamental para a classificação do B nítico e influencia outras propriedades. Os Latossolos estudados apresentaram aspecto bastante parecido entre si, diferindo do Nitossolo, principalmente em relação à estrutura. Quando presente em Latossolos, 
Quadro 1. Morfologia dos solos Latossolo Vermelho eutroférrico (LD) e Nitossolo Vermelho distroférrico (ND) em sistema de plantio direto e do Latossolo Vermelho eutroférrico (LC) sob preparo convencional

\begin{tabular}{|c|c|c|c|c|c|c|}
\hline Horizonte & Prof. & Cor & Textura & Estrutura & $\begin{array}{l}\text { Cerosidade e Consistência } \\
\text { (solo úmido, solo molhado) }\end{array}$ & Transição \\
\hline \multicolumn{7}{|c|}{ Perfil Latossolo Vermelho eutroférrico em plantio direto (LD) } \\
\hline Ap1 & $0-12$ & $\begin{array}{l}\text { 10R } 3 / 3 \text { bruno- } \\
\text { avermelhado } \\
\text { escuro }\end{array}$ & Argilosa & $\begin{array}{l}\text { Fraca média blocos subangulares, se } \\
\text { desfaz em forte peq. e muito peq. } \\
\text { Granular }\end{array}$ & $\begin{array}{l}\text { Muito friável, muito } \\
\text { plástico e pegajoso }\end{array}$ & Difusa e plana \\
\hline Ap2 & $12-32$ & $\begin{array}{l}\text { 10R } 3 / 3 \text { bruno- } \\
\text { avermelhado } \\
\text { escuro }\end{array}$ & Argilosa & $\begin{array}{l}\text { Fraca peq. E média blocos } \\
\text { subangulares, se desfaz em forte peq. } \\
\text { e muito peq. granular }\end{array}$ & $\begin{array}{l}\text { Muito friável, muito } \\
\text { plástico e muito pegajoso }\end{array}$ & Difusa e plana \\
\hline BA & $32-58$ & $\begin{array}{l}\text { 10R } 3 / 4 \text { vermelho- } \\
\text { escuro }\end{array}$ & $\begin{array}{l}\text { Muito } \\
\text { argilosa }\end{array}$ & $\begin{array}{l}\text { Fraca a moderada peq. e média blocos } \\
\text { subangulares, se desfaz em forte peq. } \\
\text { e m uito peq. média granular }\end{array}$ & $\begin{array}{l}\text { Cerosidade fraca pouca, } \\
\text { muito friável, plástico e } \\
\text { pegajoso }\end{array}$ & Difusa e plana \\
\hline Bw1 & $58-92$ & $\begin{array}{l}\text { 10R } 3 / 4 \text { vermelho- } \\
\text { escuro }\end{array}$ & $\begin{array}{l}\text { Muito } \\
\text { argilosa }\end{array}$ & Forte peq. a muito peq. Granular & $\begin{array}{l}\text { Muito friável, plástico e } \\
\text { pegajoso }\end{array}$ & Difusa e plana \\
\hline $\mathrm{Bw} 2$ & $92-140$ & $\begin{array}{l}\text { 10R } 3 / 4 \text { vermelho- } \\
\text { escuro }\end{array}$ & $\begin{array}{l}\text { Muito } \\
\text { argilosa }\end{array}$ & Forte muito peq. Granular & $\begin{array}{l}\text { Muito friável, plástico e } \\
\text { pegajoso }\end{array}$ & Difusa e plana \\
\hline Bw3 & $140-200+$ & $\begin{array}{l}\text { 10R } 3 / 4 \text { vermelho- } \\
\text { escuro }\end{array}$ & $\begin{array}{l}\text { Muito } \\
\text { argilosa }\end{array}$ & Forte muito peq. Granular & $\begin{array}{l}\text { Muito friável, plástico e } \\
\text { pegajoso }\end{array}$ & \\
\hline \multicolumn{7}{|c|}{ Perfil Nitossolo Vermelho distroférrico em plantio direto (ND) } \\
\hline Ap1 & $0-12$ & $\begin{array}{l}2,5 \text { YR } 3 / 4 \text { bruno- } \\
\text { avermelhado } \\
\text { escuro }\end{array}$ & $\begin{array}{l}\text { Muito } \\
\text { argilosa }\end{array}$ & Forte grande blocos subangulares & $\begin{array}{l}\text { Firme, muito plástico e } \\
\text { muito pegaojoso }\end{array}$ & Clara plana \\
\hline Ap2 & $12-27$ & $\begin{array}{l}2,5 \text { YR } 3 / 4 \text { bruno- } \\
\text { avermelhado } \\
\text { escuro }\end{array}$ & $\begin{array}{l}\text { Muito } \\
\text { argilosa }\end{array}$ & $\begin{array}{l}\text { Forte média e grande blocos } \\
\text { subangulares }\end{array}$ & $\begin{array}{l}\text { Muito firme, muito plástico } \\
\text { e muito pegajoso }\end{array}$ & $\begin{array}{l}\text { Abrupta e } \\
\text { ondulada }(20 \text { - } \\
34 \mathrm{~cm})\end{array}$ \\
\hline Bt1 & $27-53$ & $\begin{array}{l}2,5 \text { YR } 3 / 4 \text { bruno- } \\
\text { avermelhado } \\
\text { escuro }\end{array}$ & $\begin{array}{l}\text { Muito } \\
\text { argilosa }\end{array}$ & $\begin{array}{l}\text { Forte média e grande blocos } \\
\text { angulares e subangulares }\end{array}$ & $\begin{array}{l}\text { Cerosidade comum e forte, } \\
\text { muito firme, muito plástico } \\
\text { e muito pegajoso }\end{array}$ & $\begin{array}{l}\text { Gradual e } \\
\text { ondulada }(50- \\
55 \mathrm{~cm})\end{array}$ \\
\hline Bt2 & $53-98$ & $\begin{array}{l}2,5 \text { YR } 3 / 4 \text { bruno- } \\
\text { avermelhado } \\
\text { escuro }\end{array}$ & $\begin{array}{l}\text { Muito } \\
\text { argilosa }\end{array}$ & $\begin{array}{l}\text { Forte média e grande blocos } \\
\text { angulares e subangolares }\end{array}$ & $\begin{array}{l}\text { Cerosidade comum e forte, } \\
\text { firme muito plástico a } \\
\text { plástico e muito pegajoso }\end{array}$ & Difusa e plana \\
\hline Bw1 & $98-130$ & $\begin{array}{l}\text { 10R } 3 / 4 \text { vermelho- } \\
\text { escuro }\end{array}$ & $\begin{array}{l}\text { Muito } \\
\text { argilosa }\end{array}$ & $\begin{array}{l}\text { Fraca e moderada média, blocos } \\
\text { subangulares, se desfaz em forte } \\
\text { muito peq. Granular }\end{array}$ & $\begin{array}{l}\text { Friável, muito plástico e } \\
\text { plástico e muito pegajoso }\end{array}$ & Difusa e plana \\
\hline Bw2 & $130-190$ & $\begin{array}{l}\text { 10R } 3 / 4 \text { vermelho- } \\
\text { escuro }\end{array}$ & $\begin{array}{l}\text { Argilosa, } \\
\text { maior quan- } \\
\text { tidade de silte }\end{array}$ & $\begin{array}{l}\text { Fraca média blocos subangulares, } \\
\text { sedesfaz em forte muito peq.granular }\end{array}$ & $\begin{array}{l}\text { Muito friável, plástico e } \\
\text { pegajoso }\end{array}$ & \\
\hline \multicolumn{7}{|c|}{ Perfil Latossolo Vermelho eutroférrico em preparo convencional (LC) } \\
\hline Ap1 & $0-15$ & $\begin{array}{l}2,5 \text { YR } 3 / 3 \text { bruno- } \\
\text { avermelhado } \\
\text { escuro }\end{array}$ & Argilosa & $\begin{array}{l}\text { Moderada média e pequena blocos } \\
\text { subangulares,se desfaz em forte muito } \\
\text { pequena e média granular }\end{array}$ & $\begin{array}{l}\text { Muito friável plástico e } \\
\text { pegajoso }\end{array}$ & Difusa e plana \\
\hline $\mathrm{AB}$ & $15-40$ & $\begin{array}{l}2,5 \text { YR } 3 / 4 \text { bruno- } \\
\text { avermelhado } \\
\text { escuro }\end{array}$ & $\begin{array}{l}\text { Muito } \\
\text { argilosa }\end{array}$ & $\begin{array}{l}\text { Moderada peq. e média blocos } \\
\text { subangulares e granular }\end{array}$ & $\begin{array}{l}\text { Muito friável, muito } \\
\text { plástico e muito pegajoso }\end{array}$ & Difusa e plana \\
\hline Bw1 & $40-76$ & $\begin{array}{l}\text { 10R } 3 / 4 \text { vermelho- } \\
\text { escuro }\end{array}$ & $\begin{array}{l}\text { Muito } \\
\text { argilosa }\end{array}$ & $\begin{array}{l}\text { Fraca e pequena e média blocos } \\
\text { subangulares, se desfaz em forte peq. } \\
\text { a muito peq.granular }\end{array}$ & $\begin{array}{l}\text { Cerosidade fraca a pouca, } \\
\text { friável a muito friável, } \\
\text { plástico e pegajoso }\end{array}$ & Difusa e plana \\
\hline Bw2 & $76-132$ & $\begin{array}{l}\text { 10R } 3 / 4 \text { vermelho- } \\
\text { escuro }\end{array}$ & $\begin{array}{l}\text { Muito } \\
\text { argilosa }\end{array}$ & $\begin{array}{l}\text { Fraca média e grande blocos } \\
\text { subangulares, se desfaz em forte } \\
\text { muito peq. Granular, }\end{array}$ & $\begin{array}{l}\text { Muito friável, ligeiramente } \\
\text { plástrico e pegajoso }\end{array}$ & Difusa eplana \\
\hline Bw3 & $132-200+$ & $\begin{array}{l}\text { 10R } 3 / 4 \text { vermelho- } \\
\text { escuro }\end{array}$ & $\begin{array}{l}\text { Muito } \\
\text { argilosa }\end{array}$ & $\begin{array}{l}\text { Fraca e média e grande blocos } \\
\text { subangulares, se desfaz em fortes } \\
\text { muito peq. Granular }\end{array}$ & $\begin{array}{l}\text { Muito friável, ligieramente } \\
\text { plástico e pegajoso }\end{array}$ & \\
\hline
\end{tabular}

a estrutura em blocos tem grau de desenvolvimento fraco (horizontes A e Bw) a moderado (horizonte A), enquanto no horizonte B nítico do solo ND a estrutura em blocos tem grau de desenvolvimento forte (Santos et al., 2006).

A consistência do solo úmido foi outro atributo morfológico que diferenciou claramente B latossólico, muito friável e friável, de B nítico, muito firme e firme. Pela forma de avaliação desse atributo - aplicação de pressão ao torrão - e pelo estado de umidade mais próximo ao do solo no campo, espera-se que a consistência do solo úmido guarde ampla equivalência com propriedades mensuráveis que avaliam a resistência dos agregados à pressão, a exemplo da sua resistência à penetração.

Outro atributo morfológico diferencial do solo ND para os Latossolos apresentados no quadro 1, e que é característico de horizontes B níticos, é a cerosidade, 
que de 0,27 a 0,98 $\mathrm{m}$ de profundidade tem ocorrência comum e em grau forte no solo ND (Nitossolo). Além dos atributos já citados, parte deles típica da diferenciação entre as ordens de Nitossolos e Latossolos, a transição entre os horizontes, que não é um diferencial entre essas duas ordens, se dá de forma abrupta do A para o Bt no ND e de maneira gradual ou difusa nos Latossolos estudados. Essa diferenciação morfológica entre horizontes A e Bt no ND está relacionada sobretudo a maior grau de adensamento no topo do horizonte Bt. À exceção da espessura do solum (horizontes $\mathrm{A}+\mathrm{B}$ ), menor no solo ND, os demais atributos morfológicos são bastante semelhantes entre os três perfis estudados. Cooper \& Vidal-Torrado (2005) também identificaram a influência dos atributos morfológicos sobre o comportamento físico-hídrico dos horizontes B níticos e B latossólicos, que se diferenciaram principalmente no grau de cerosidade e nas zonas microagregadas. O B nítico apresentou cerosidade comum e moderada e desaparecimento das zonas microagregadas, e no B latossólico a cerosidadade se apresentou comum e fraca com presença de zonas microagregadas.

\section{Química e granulometria do solo}

Os quadros 2 e 3 mostram que os dois Latossolos (LC e LD) têm elevado teor de ferro e baixa atividade da fração argila, saturação por bases intermediária, baixos a nulos teores de Al trocável e reação moderadamente ácida - condições típicas de Latossolos desenvolvidos de rochas básicas. A análise granulométrica desses Latossolos revela textura argilosa, que passa a ser muito argilosa com a profundidade e apresentar teores de silte inferiores a $140 \mathrm{~g} \mathrm{~kg}^{-1}$.

O Nitossolo (ND) (Quadro 4) mostra-se quimicamente muito semelhante aos Latossolos estudados, com saturação por bases ligeiramente superior à daqueles, apresentando caráter eutrófico a partir de $1 \mathrm{~m}$ e reação moderadamente ácida a praticamente neutra. Até mesmo o teor de argila em profundidade no Nitossolo tem gradiente pequeno. Nos atributos apresentados no quadro 4, a diferença mais marcante do Nitossolo encontra-se nos teores de silte mais elevados, de 150 a $200 \mathrm{~g} \mathrm{~kg}^{-1}$, que, junto com a menor profundidade do solo e mais elevada saturação por bases e índice $\mathrm{Ki}$, expressam o menor grau de desenvolvimento pedogenético do ND em relação aos solos LC e LD. Os elevados teores de $\mathrm{Fe}_{2} \mathrm{O}_{3}$ no horizonte $\mathrm{B}$ dos três perfis, com um pouco menos no Bt do ND, e o $\Delta \mathrm{pH}$ positivo ou próximo a zero nos três perfis a partir de 1,0 m condizem com a estrutura forte muito pequena granular desses horizontes (Ferreira et al., 1997), indicativa do predomínio de microagregados.

Quadro 2. Dados analíticos do Latossolo Vermelho distroférrico típico sob plantio direto

\begin{tabular}{|c|c|c|c|c|c|c|c|}
\hline \multirow{2}{*}{ Variável } & \multirow{2}{*}{ Unidade } & \multicolumn{6}{|c|}{ Horizonte/Profundidade (m) } \\
\hline & & Ap1/0-0,12 & Ap2/0,12-0,32 & $\mathrm{BA} / 0,32-0,58$ & $\mathrm{Bw} 1 / 0,58-0,92$ & $\mathrm{Bw} 2 / 0,92-0,14$ & $\overline{\mathrm{Bw} 3 / 0,14-0,2}$ \\
\hline \multicolumn{8}{|c|}{ Análise química } \\
\hline $\mathrm{pH} \mathrm{H}{ }_{2} \mathrm{O}$ & & 5,2 & 5,0 & 5,5 & 5,5 & 5,9 & 6,3 \\
\hline $\mathrm{pH} \mathrm{KCl}$ & & 4,8 & 4,6 & 5,2 & 5,4 & 5,9 & 6,4 \\
\hline$\Delta \mathrm{pH}$ & & $-0,4$ & $-0,4$ & $-0,3$ & $-0,1$ & 0,0 & $+0,1$ \\
\hline $\mathrm{pH} \mathrm{CaCl}{ }_{2}$ & & 4,7 & 4,7 & 5,1 & 5,3 & 5,5 & 5,7 \\
\hline M. Org. & $\mathrm{g} \mathrm{kg}$ & 33,0 & 28,0 & 18,0 & 18,0 & 13,0 & 6,0 \\
\hline $\mathrm{C}$ & dag kg-1 & 1,9 & 1,6 & 1,0 & 1,0 & 0,8 & 0,3 \\
\hline $\mathrm{P}$ & $\mathrm{mg} \mathrm{kg}^{-1}$ & 22,0 & 4,0 & 1,0 & 1,0 & 1,0 & 1,0 \\
\hline $\mathrm{K}^{+}$ & $\mathrm{mmol}_{\mathrm{c}} \mathrm{kg}^{-1}$ & 7,2 & 5,4 & 1,7 & 0,9 & 0,6 & 1,5 \\
\hline $\mathrm{Ca}^{2+}$ & $\mathrm{mmol}_{\mathrm{c}} \mathrm{kg}^{-1}$ & 33 & 16 & 20 & 19 & 13 & 16 \\
\hline $\mathrm{Mg}^{2+}$ & $\mathrm{mmol}_{\mathrm{c}} \mathrm{kg}^{-1}$ & 10 & 8 & 7 & 6 & 3 & 3 \\
\hline $\mathrm{Al}^{3+}$ & $\mathrm{mmol}_{\mathrm{c}} \mathrm{kg}^{-1}$ & 2 & 2 & 0 & 0 & 0 & 0 \\
\hline $\mathrm{H}+\mathrm{Al}$ & $\mathrm{mmol}_{\mathrm{c}} \mathrm{kg}^{-1}$ & 57 & 54 & 34 & 27 & 21 & 16 \\
\hline SB & $\mathrm{mmol}_{\mathrm{c}} \mathrm{kg}^{-1}$ & 50,2 & 29,4 & 28,7 & 25,9 & 16,6 & 20,5 \\
\hline $\mathrm{T}$ & $\mathrm{mmol}_{\mathrm{c}} \mathrm{kg}^{-1}$ & 107,2 & 83,4 & 62,7 & 52,9 & 37,6 & 36,5 \\
\hline V & $\%$ & 47 & 35 & 46 & 49 & 44 & 56 \\
\hline $\mathrm{m}$ & $\%$ & 4 & 6 & 0 & 0 & 0 & 0 \\
\hline $\mathrm{SiO}_{2}$ & dag $\mathrm{kg}^{-1}$ & & & & & 13,40 & \\
\hline $\mathrm{Al}_{2} \mathrm{O}_{3}$ & dag kg-1 & & & & & 25,76 & \\
\hline $\mathrm{Fe}_{2} \mathrm{O}_{3}$ & dag kg-1 & & & & & 23,49 & \\
\hline $\mathrm{TiO}_{2}$ & dag kg-1 & & & & & 3,32 & \\
\hline $\mathrm{MnO}$ & dag $\mathrm{kg}^{-1}$ & & & & & 0,10 & \\
\hline $\mathrm{Ki}$ & & & & & & 0,88 & \\
\hline $\mathrm{Kr}$ & & & Análise & ranulométrica & & 0,56 & \\
\hline Argila & $\mathrm{g} \mathrm{kg}^{-1}$ & 588 & 563 & 663 & 663 & 663 & 663 \\
\hline Silte & $\mathrm{g} \mathrm{kg}^{-1}$ & 160 & 217 & 130 & 139 & 132 & 128 \\
\hline Areia total & $\mathrm{g} \mathrm{kg}^{-1}$ & 253 & 221 & 207 & 198 & 205 & 209 \\
\hline Areia grossa & $\mathrm{g} \mathrm{kg}^{-1}$ & 148 & 125 & 115 & 105 & 108 & 113 \\
\hline Areia fina & $\mathrm{g} \mathrm{kg}^{-1}$ & 105 & 96 & 92 & 93 & 98 & 96 \\
\hline
\end{tabular}


Quadro 3. Dados analíticos do Latossolo Vermelho distroférrico típico sob plantio convencional

\begin{tabular}{|c|c|c|c|c|c|c|c|}
\hline \multirow{2}{*}{ Variável } & \multirow{2}{*}{ Unidade } & \multicolumn{6}{|c|}{ Horizonte/Profundidade (m) } \\
\hline & & Ap1/0-0,12 & Ap2/0,12-0,32 & $\mathrm{BA} / \mathbf{0 , 3 2 - 0 , 5 8}$ & Bw1/0,58-0,92 & Bw2/0,92-0,14 & Bw3/0,14-0,2 \\
\hline \multicolumn{8}{|c|}{ Análise química } \\
\hline $\mathrm{pH} \mathrm{H} \mathrm{H}_{2} \mathrm{O}$ & & 5,8 & 6,0 & 6,0 & 6,0 & & 6,2 \\
\hline $\mathrm{pH} \mathrm{KCl}$ & & 5,0 & 5,1 & 5,5 & 5,8 & & 6,1 \\
\hline$\Delta \mathrm{pH}$ & & $-0,8$ & $-0,9$ & $-0,5$ & $-0,2$ & & $-0,1$ \\
\hline $\mathrm{pH} \mathrm{CaCl}{ }_{2}$ & & 5,3 & 5,4 & 5,5 & 5,6 & & 5,8 \\
\hline M. Org. & $\mathrm{g} \mathrm{kg}^{-1}$ & 31,0 & 20,0 & 13,0 & 10,0 & & 13,0 \\
\hline $\mathrm{C}$ & dag $\mathrm{kg}^{-1}$ & 1,80 & 1,16 & 0,75 & 0,58 & & 0,75 \\
\hline $\mathrm{P}$ & $\mathrm{mg} \mathrm{kg}^{-1}$ & 7,0 & 2,0 & 1,0 & 1,0 & & 1,0 \\
\hline $\mathrm{K}^{+}$ & $\mathrm{mmol}_{\mathrm{c}} \mathrm{kg}^{-1}$ & 4 & 1,8 & 0,4 & 0,2 & & 0,7 \\
\hline $\mathrm{Ca}^{2+}$ & $\mathrm{mmol}_{\mathrm{c}} \mathrm{kg}^{-1}$ & 37 & 19 & 15 & 14 & & 13 \\
\hline $\mathrm{Mg}^{2+}$ & $\mathrm{mmol}_{\mathrm{c}} \mathrm{kg}^{-1}$ & 18 & 11 & 4 & 2 & & 2 \\
\hline $\mathrm{Al}^{3+}$ & $\mathrm{mmol}_{\mathrm{c}} \mathrm{kg}^{-1}$ & 0 & 0 & 0 & 0 & & 0 \\
\hline $\mathrm{H}+\mathrm{Al}$ & $\mathrm{mmol}_{\mathrm{c}} \mathrm{kg}^{-1}$ & 54 & 40 & 26 & 22 & & 16 \\
\hline SB & $\mathrm{mmol}_{\mathrm{c}} \mathrm{kg}^{-1}$ & 59,0 & 31,8 & 19,4 & 16,2 & & 15,7 \\
\hline $\mathrm{T}$ & $\mathrm{mmol}_{\mathrm{c}} \mathrm{kg}^{-1}$ & 113,0 & 71,8 & 45,4 & 38,2 & & 31,7 \\
\hline $\mathrm{V}$ & $\%$ & 52 & 44 & 43 & 42 & & 50 \\
\hline $\mathrm{m}$ & $\%$ & 0 & 0 & 0 & 0 & & 0 \\
\hline $\mathrm{SiO}_{2}$ & dag $\mathrm{kg}^{-1}$ & & & & 13,5 & & \\
\hline $\mathrm{Al}_{2} \mathrm{O}_{3}$ & dag kg-1 & & & & 24,7 & & \\
\hline $\mathrm{Fe}_{2} \mathrm{O}_{3}$ & dag kg-1 & & & & 25,2 & & \\
\hline $\mathrm{TiO}_{2}$ & dag kg-1 & & & & 3,3 & & \\
\hline $\mathrm{MnO}$ & dag kg-1 & & & & 0,07 & & \\
\hline $\mathrm{Ki}$ & & & & & 0,93 & & \\
\hline $\mathrm{Kr}$ & \multicolumn{7}{|c|}{ Análise granulométrica } \\
\hline Argila & $\mathrm{g} \mathrm{kg}^{-1}$ & 563 & $613^{\text {Andise }}$ & 688 & 663 & & 663 \\
\hline Silte & $\mathrm{g} \mathrm{kg}^{-1}$ & 175 & 165 & 102 & 122 & & 115 \\
\hline Areia total & $\mathrm{g} \mathrm{kg}^{-1}$ & 263 & 223 & 211 & 216 & & 223 \\
\hline Areia grossa & $\mathrm{g} \mathrm{kg}^{-1}$ & 158 & 127 & 119 & 120 & & 124 \\
\hline Areia fina & $\mathrm{g} \mathrm{kg}^{-1}$ & 105 & 96 & 91 & 96 & & 99 \\
\hline
\end{tabular}

Quadro 4. Dados analíticos do Nitossolo Vermelho distroférrico latossólico sob plantio direto

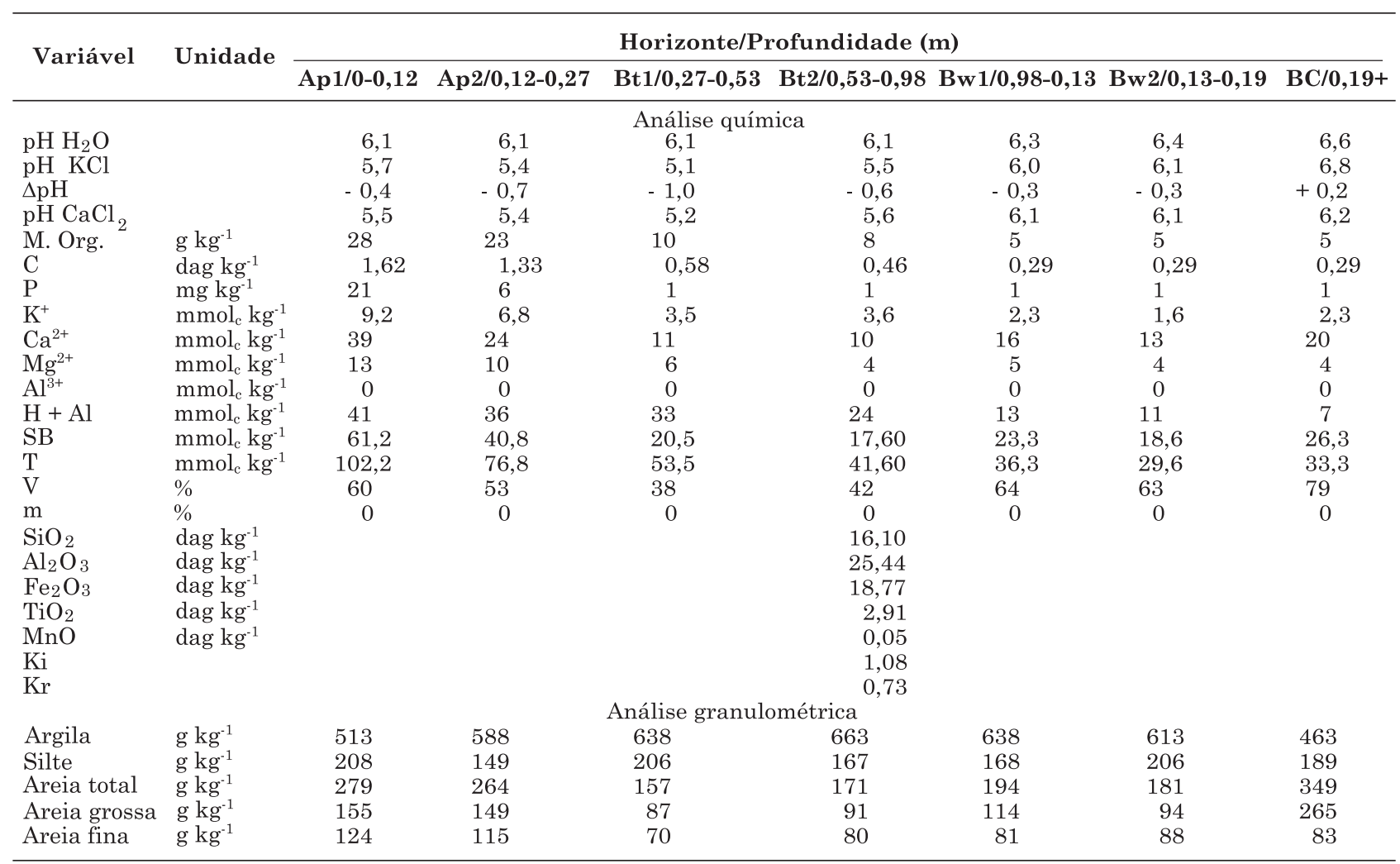




\section{Propriedades físico-hídricas}

As curvas de retenção ajustadas pelo modelo de van Genuchten (1980) na escala logarítmica, representando todos os pontos da curva, de 0,1 a $1.500 \mathrm{kPa}$, são apresentadas por cada perfil de solo (Figura 1a,b,c) e também por profundidade entre os horizontes (Figura 1d,e,f,g,h). Nos Latossolos, essas curvas apresentaram pouca diferença entre si (Figura 1). Dos três perfis, o do Nitossolo apresentou maiores teores

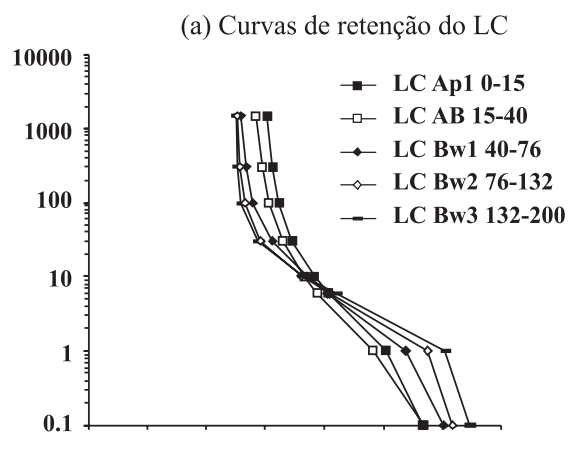

(c) Curvas de retenção do ND

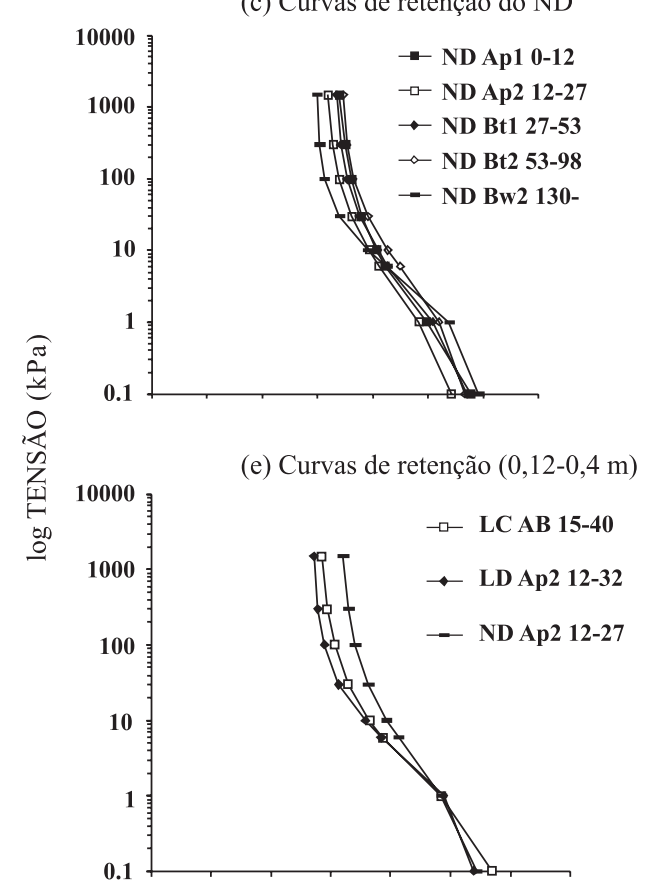

(g) Curvas de retenção (0,53-1,32 m)

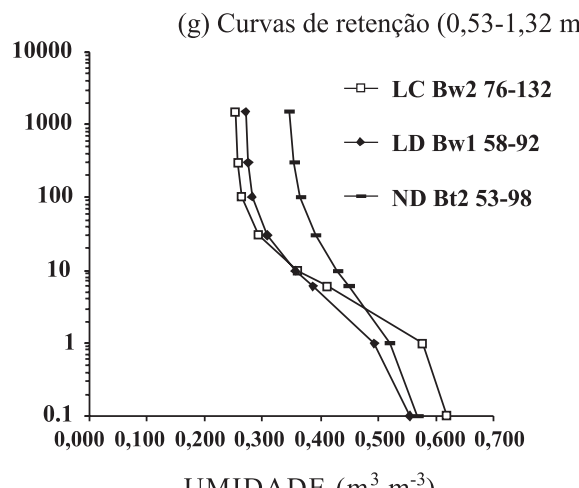

(b) Curvas de retenção do LD

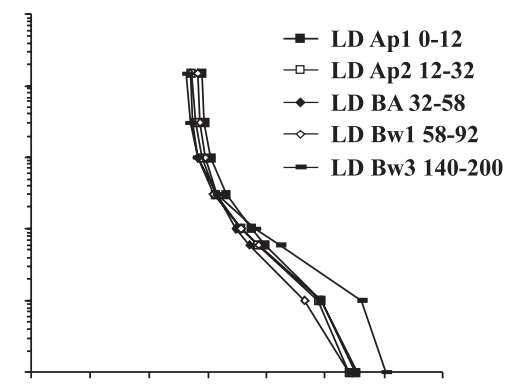

(d) Curvas de retenção $(0-0,15$ m)

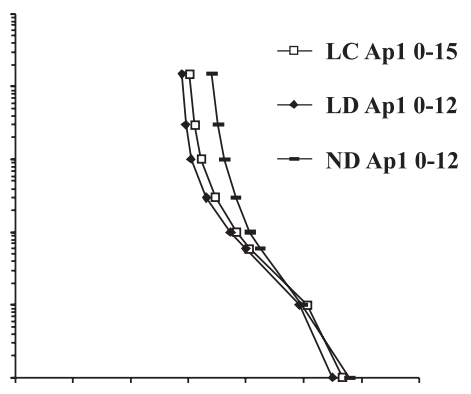

(f) Curvas de retenção $(0,27-0,76 \mathrm{~m})$

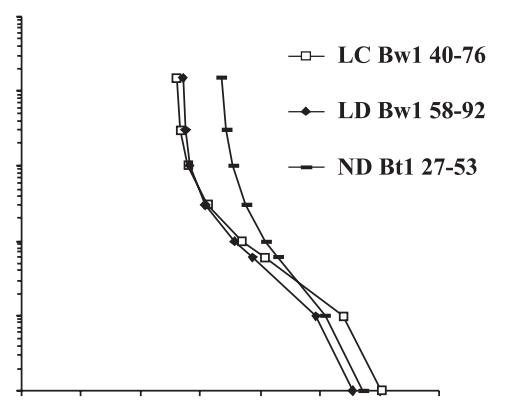

(h) Curvas de retenção (1,3-2,00 m)

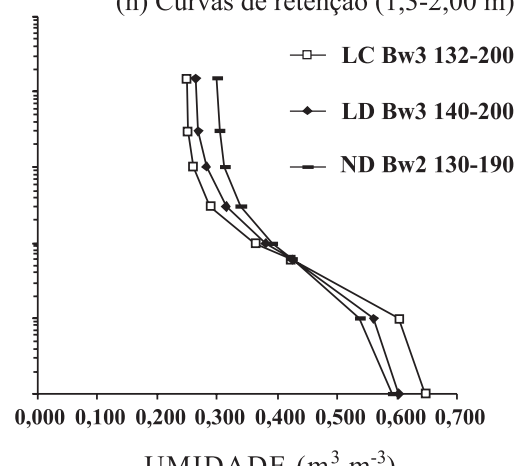

Figura 1. Curva de retenção de água para os três perfis: Latossolo Vermelho eutroférrico em plantio direto - LD (Ap1, Ap2, BA, Bw1 e Bw3), Nitossolo Vermelho distroférrico em plantio direto - ND (Ap1, Ap2, Bt1, Bt2 e Bw) e Latossolo Vermelho eutroférrico em preparo convencional - LC (Ap1, AB. Bw1, Bw2 e Bw3). 
de água nas maiores tensões (Figura 1c até h). Os horizontes $\mathrm{B}$ níticos, apesar de reterem mais água que os B latossólicos nas altas tensões, como no ponto de murcha permanente $(1.500 \mathrm{kPa})$, retêm teores de água equivalentes aos dos Latossolos em $10 \mathrm{kPa}$ (capacidade de campo), ou seja, apresentam curvas menos inflexionadas. Isso faz com que os horizontes $\mathrm{B}$ níticos estudados apresentem teores de água disponível ligeiramente inferiores ao dos B latossólicos - aspecto importante quando se considera o manejo desses solos. Nessa linha, Cooper \& Vidal-Torrado (2005) chegaram a identificar no solo com horizonte B nítico um comportamento caracterizado por maior retenção de água e diminuição na condução de água do que no solo com B latossólico.

Ainda em relação ao manejo de horizontes $\mathrm{B}$ níticos, é de se esperar que maiores teores de água (em relação ao B latossólico) na tensão de $1.500 \mathrm{kPa}$ sejam responsáveis pela maior tolerância das plantas a períodos de seca mais prolongados em Nitossolos que em Latossolos. Espera-se que, quando o solo atinja o ponto de murcha, a água retida em tensões maiores que $1.500 \mathrm{kPa}$ seja redistribuída para poros sob menores tensões. Nesse caso, o horizonte nítico teria mais água para essa redistribuição. Essa retenção de água no Nitossolo é maior nos horizontes com profundidades entre 0,27 e $0,76 \mathrm{~m}$ e entre $0,53 \mathrm{e}$ 1,32 m, decrescendo nos horizontes subjacentes Bw, como também nos horizontes sobrejacentes (horizontes A) (Figura 1.d até 1.h). Assim, pela curva de retenção, a diferenciação entre os solos estudados se dá nos horizontes diagnósticos de subsuperfície Bt e Bw.

Entre o horizonte B latossólico e o B nítico dos solos estudados, o que pode contribuir para uma diferença na retenção de água são, principalmente, a estrutura e a distribuição granulométrica (Quadros 1 a 4). O arranjo estrutural em blocos e em grau forte contribui para a redução da porosidade total no horizonte B nítico, expresso pela redução da macroporosidade e aumento da microporosidade (Quadro 5). Os maiores teores de silte no ND podem também exercer pequena influência na retenção de água, porém, apesar dos teores intermediários a elevados de silte no B latossólico (206 $\mathrm{g} \mathrm{kg}^{-1}$ ) do solo ND, a retenção de água do horizonte Bw2 no ND tem comportamento distinto, retendo menos água que o $\mathrm{B}$ nítico. Cabe ressaltar que o elevado teor de silte pode estar associado ao problema de dispersão durante a análise, podendo ter sido considerados como silte os microagregados de argila do mesmo tamanho das partículas de silte. Horizontes B níticos, como o do solo estudado (ND), têm estrutura de grau forte ou moderado e em blocos, o que favorece maior retenção de água em microporos, devido à compacidade do empacotamento. Essa maior compacidade está expressa pelos valores de densidade do solo do B nítico (Bt1 = 1,53 e Bt2 = 1,72 $\mathrm{kg} \mathrm{dm}^{-3}$ ), em comparação com a média da densidade dos horizontes $\mathrm{B}$ latossólicos (Bw1 = 1,17 e Bw2 = $1,14 \mathrm{~kg} \mathrm{dm}^{-3}$ ), mostrando que a porosidade total do horizonte nítico é bem menor (Quadro 5). As semelhanças observadas entre o Nitossolo e os Latossolos nas baixas tensões e as diferenças nas tensões elevadas (10 a $1.500 \mathrm{kPa}$ ) concordam com a proporção de macroporos semelhantes entre esses solos (água gravitacional) e com a maior proporção de microporos em relação à porosidade total (razão microporos/poros totais) no Nitossolo, particularmente nos horizontes B níticos (Bt), se comparados aos Latossolos (Quadro 5).

Quadro 5. Macroporos (MP), microporos (mP), porosidade total (PT), densidade (Ds) e razão microporos/ poros totais (mP/PT) nos horizontes dos três perfis do solo Latossolo Vermelho eutroférrico em plantio direto (LD), Latossolo Vermelho eutroférrico em preparo convencional (LC) e Nitossolo Vermelho distroférrico em plantio direto (ND)

\begin{tabular}{|c|c|c|c|c|c|c|}
\hline Horizonte & Profundidade & MP & $\mathbf{m P}$ & $\mathbf{P T}$ & Ds & $\mathrm{mP} / \mathrm{PT}$ \\
\hline \multirow{2}{*}{\multicolumn{7}{|c|}{$\underset{\text { Latossolo Vermelho eutroférrico em plantio direto (LD) }}{\mathrm{m}} \mathrm{m}^{3} \mathrm{~m}^{-3} \overline{\text { dire }}$}} \\
\hline & & & & & & \\
\hline Ap 1 & $0-0,12$ & 0,16 & 0,40 & 0,56 & 1,23 & 71,1 \\
\hline Ap 2 & $0,12-0,32$ & 0,16 & 0,39 & 0,55 & 1,20 & 70,9 \\
\hline $\mathrm{BA}$ & $0,32-0,58$ & 0,19 & 0,37 & 0,56 & 1,19 & 65,8 \\
\hline Bw1 & $0,58-0,92$ & 0,18 & 0,39 & 0,57 & 1,15 & 69,0 \\
\hline Bw3 & $1,40-2,00+$ & 0,18 & 0,43 & 0,61 & 1,13 & 71,0 \\
\hline \multicolumn{7}{|c|}{ Latossolo Vermelho eutroférrico em preparo convencional (LC) } \\
\hline Ap1 & $0-0,15$ & 0,17 & 0,40 & 0,58 & 1,33 & 69,8 \\
\hline $\mathrm{AB}$ & $0,15-0,40$ & 0,20 & 0,39 & 0,59 & 1,24 & 66,2 \\
\hline Bw1 & $0,40-0,76$ & 0,20 & 0,41 & 0,61 & 1,18 & 66,9 \\
\hline Bw2 & $0,76-1,32$ & 0,20 & 0,42 & 0,62 & 1,13 & 67,1 \\
\hline Bw3 & $1,32-2,00+$ & 0,22 & 0,43 & 0,65 & 1,44 & 66,3 \\
\hline \multicolumn{7}{|c|}{ Nitossolo Vermelho distroférrico em plantio direto (ND) } \\
\hline Ap1 & $0-0,12$ & 0,17 & 0,43 & 0,60 & 1,86 & 72,2 \\
\hline Ap2 & $0,12-0,27$ & 0,15 & 0,42 & 0,57 & 1,83 & 74,0 \\
\hline Bt1 & $0,27-0,53$ & 0,16 & 0,43 & 0,59 & 1,54 & 72,9 \\
\hline Bt2 & $0,53-0,98$ & 0,13 & 0,46 & 0,59 & 1,73 & 78,0 \\
\hline Bw2 & $1,30-1,90+$ & 0,17 & 0,43 & 0,60 & 1,51 & 71,6 \\
\hline
\end{tabular}


Quando se analisa a retenção de água de 0,0 até 0,30 ou $0,40 \mathrm{~m}$ de profundidade (Figura 1a,b), a porosidade e a densidade do solo (Quadro 5), observase que o manejo não mostrou tendências claras de diferenciação entre os Latossolos (LC vs LD). As condições do solo no momento da coleta (tempo após preparo e plantio) podem ter favorecido esse resultado, já que o solo sob preparo convencional encontrava-se há três meses em pousio, o que pode ter colaborado para as semelhanças encontradas.

\section{Variabilidade espacial da resistência do solo à penetração e à infiltração de água}

No quadro 6 estão os parâmetros estatísticos da resistência do solo à penetração e da resistência do solo à infiltração da água nos três perfis de 0 a $1,50 \mathrm{~m}$. Houve tendência à normalidade de distribuição de frequência em todos os dados, pois assimetria e curtose se aproximam de zero. Os coeficientes de variação são classificados como médios, de acordo com os critérios estabelecidos por Warrick \& Nielsen (1980). Nota-se que o Nitossolo apresentou maior média de resistência à penetração e maior média de resistência à infiltração de água em relação aos Latossolos semelhante ao verificado por Jorge \& Prado (1988). Isso está de acordo com a morfologia observada e com as demais propriedades físicas (Quadros 2 e 5), indicando que o perfil do Nitossolo tem consistência mais firme que o do Latossolo. Grau forte de desenvolvimento de estrutura em blocos caracteriza unidades estruturais com faces de contato bem definidas, o que pode significar inclusive fendilhamento no período seco, que se reflete em poros de tamanho grande, onde a água flui mais rapidamente. Estrutura forte em blocos significa torrões coesos internamente, mas fraturados entre torrões. Essa coesão interna contribui para maior resistência do solo à penetração e retenção de água nos microporos, ao passo que o fraturamento entre blocos contribui para os valores mais elevados de condutividade da água no solo. Assim, resumindo os aspectos relacionados às propriedades físicas e atributos morfológicos em Nitossolos em relação a
Latossolos, pode-se dizer que a estrutura forte, em blocos subangulares, do ND permite (1) nos blocos: maior retenção de água e maior resistência à penetração; e (2) nas fraturas ou superfícies de contato entre blocos: maior permeabilidade.

Os resultados referentes aos ajustes dos semivariogramas são mostrados no quadro 7 e na figura 2. O grau de dependência espacial (GD), segundo Zimback (2001), varia de fraco a moderado, indicando que a amostragem deveria ser mais intensa, ou seja, com distância entre pontos menor do que $0,10 \mathrm{~m}$. Apenas para a resistência à penetração do Latossolo com preparo convencional (LC) houve grau de dependência espacial forte.

Medições localizadas próximas mostraram ser mais parecidas entre si do que aquelas separadas por distâncias maiores, pois em todos os casos (Quadro 7 e Figura 2) a semivariância entre amostras aumentou com a distância até um valor máximo, no qual se estabilizou em um patamar $\left(\mathrm{Co}+\mathrm{C}_{1}\right)$ correspondente à distância-limite de dependência espacial, conhecida como alcance, que variou de 0,06 a 0,6 m. Medições localizadas a distâncias maiores que o alcance terão distribuição aleatória e, por isso, serão independentes entre si (Vieira, 2000). Isso significa que a estrutura do solo, de acordo com análise espacial da resistência do solo à penetração e da resistência do solo à infiltração da água, varia verticalmente em pequenas distâncias, o que faz sentido pedologicamente, pois a variação vertical indica as diferenças entre horizontes num mesmo perfil de solo.

A resistência à infiltração de água no Latossolo sob plantio direto (LD) foi a única que mostrou semivariograma cujo modelo ajustado não foi o esférico e sim o hole effect, que caracteriza fenômenos que oscilam em pequenas distâncias, resultando em valores de alcance (A) inferiores aos dos demais modelos de ajuste (Quadro 7 e Figura 2e). A razão para isso pode estar associada ao sistema de plantio direto, que, pelo não revolvimento periódico do solo (homogeneização), permite que se desenvolvam maiores diferenças na estruturação do solo, as quais podem afetar a movimentação da água a pequenas distâncias.

Quadro 6. Estatística descritiva para resistência do solo à penetração $\left(\mathrm{RP}, \mathrm{kg}^{\mathrm{c}} \mathrm{cm}^{-2}\right)$ e resistência à condutividade de água do solo $\left(\mathrm{PE}, \mathrm{kg} \mathrm{cm}^{-2}\right) \mathrm{em} 80$ pontos, nos três perfis do solo Latossolo Vermelho eutroférrico em plantio direto (LD), Latossolo Vermelho eutroférrico em preparo convencional (LC) e Nitossolo Vermelho distroférrico em plantio direto (ND)

\begin{tabular}{|c|c|c|c|c|c|c|c|c|}
\hline Nome & Média & Variância & $\mathbf{D P} \mathbf{P}^{(1)}$ & $\mathrm{CV}^{(2)}$ & Valor mínimo & Valor máximo & Assimetria & Curtose \\
\hline RP LD & 2,47 & 1,18 & 1,09 & 44,06 & 1,20 & 5,00 & 0,923 & $-0,309$ \\
\hline RP ND & 2,98 & 2,18 & 1,48 & 49,61 & 1,00 & 5,00 & 0,236 & $-1,522$ \\
\hline RP LC & 2,20 & 1,02 & 1,01 & 45,90 & 1,00 & 5,00 & 0,907 & $-0,092$ \\
\hline PE LD & 1,06 & 0,12 & 0,35 & 32,91 & 0,40 & 1,90 & 0,346 & $-0,259$ \\
\hline PE ND & 1,13 & 0,13 & 0,36 & 32,52 & 0,40 & 2,00 & 0,244 & $-0,570$ \\
\hline PE LC & 0,88 & 0,08 & 0,29 & 32,75 & 0,45 & 1,80 & 1,013 & 0,823 \\
\hline
\end{tabular}

(1) DP: desvio-padrão, CV: coeficiente de variação. 
Os mapas de resistência do solo à penetração e à infiltração de água estão na figura 3. Nota-se que Latossolo e Nitossolo têm comportamentos bastante

Quadro 7. Parâmetros de ajuste do semivariograma para resistência do solo à penetração $(\mathrm{RP}) \mathrm{e}$ resistência à permeabilidade de água (PE) nos perfis dos solos Latossolo Vermelho eutroférrico em plantio direto (LD), Latossolo Vermelho eutroférrico em preparo convencional (LC) e Nitossolo Vermelho distroférrico em plantio direto (ND): efeito pepita (Co), variância estrutural $\left(\mathrm{Co}+\mathrm{C}_{1}\right)$, alcance (a), coeficiente de determinação $\left(R^{2}\right)$, grau de dependência (GD) e modelo de ajuste direto - LD (Ap1, Ap2, BA, Bw1 e Bw3), Nitossolo Vermelho distroférrico em plantio direto - ND (Ap1, Ap2, Bt1, Bt2 e Bw) e Latossolo Vermelho eutroférrico em preparo convencional - LC (Ap1, AB. Bw1, Bw2 e Bw3).

\begin{tabular}{lcccccl}
\hline Variável & Co & $\mathbf{C}_{1}$ & $\mathbf{a}$ & $\mathbf{R}^{2}$ & GD & Ajuste \\
\hline & & & $\mathrm{m}$ & & $\%$ & \\
RP LD & 0,1450 & 0,0250 & 0,40 & 0,13 & 14,7 & Esférico \\
RP ND & 0,2200 & 0,1800 & 0,40 & 0,57 & 45,0 & Esférico \\
RP LC & 0,1000 & 0,4500 & 0,50 & 0,49 & 81,8 & Esférico \\
PE LD & 0,0390 & 0,0260 & 0,06 & 0,30 & 40,0 & Holle effect \\
PE ND & 0,0750 & 0,0300 & 0,60 & 0,31 & 28,6 & Esférico \\
PE LC & 0,0200 & 0,0420 & 0,55 & 0,50 & 67,7 & Esférico \\
\hline
\end{tabular}

(a) RP LD

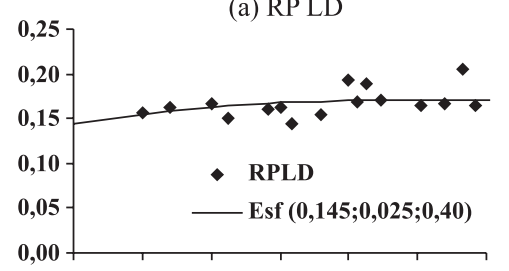

(c) RP LC

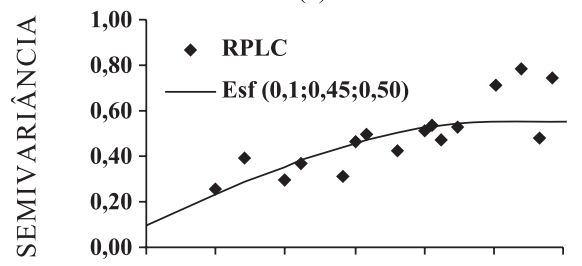

(e) PE ND

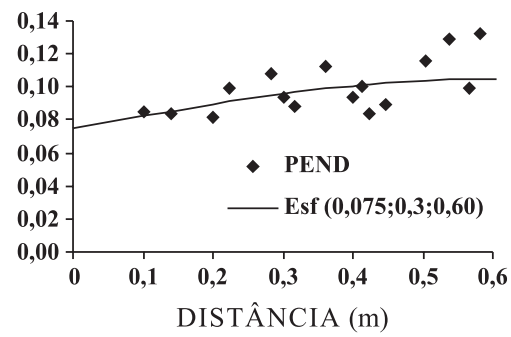

distintos com respeito aos parâmetros analisados. O perfil do Nitossolo apresenta maior resistência à penetração e à infiltração de água até cerca de $1 \mathrm{~m}$. Isso está de acordo com os maiores teores de água encontrados em locais próximos ao Nitossolo observado por Grego et al. (2004).

A variabilidade espacial da resistência do solo à penetração e a da resistência à infiltração da água na parede dos perfis, analisadas por geoestatística, mostraram-se bastante associadas à descrição morfológica e às demais propriedades físicas analisados desses perfís. Assim, em relação à resistência à penetração, observam-se dois efeitos: um provavelmente de manejo, e o outro, pedogenético. $\mathrm{O}$ efeito de manejo do solo é observado pelo maior adensamento nas camadas superficiais dos dois solos em plantio direto (Figura 3), em relação ao solo sob cultivo convencional. A camada superficial do solo no plantio direto é a que sofre maior compactação, causada principalmente pelo efeito cumulativo da pressão dos implementos agrícolas ao longo do tempo (Silva et al., 2000). Interessante também é a aparente tendência das camadas de adensamento, que é gradativo em direção à superfície, serem mais paralelas à superfície nos solos sob PD (LD e ND) (Figura 3a,b,d,e) que no solo sob cultivo convencional (Figura 3c,f), este último apresentando camadas de continuidade mais irregular (menos paralelas à superfície), o que pode ser consequência da ação dos implementos de preparo do solo. Vale lembrar

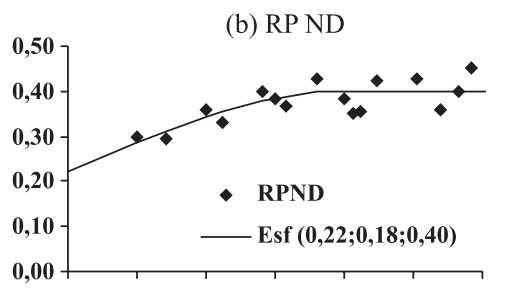

(d) PE LD

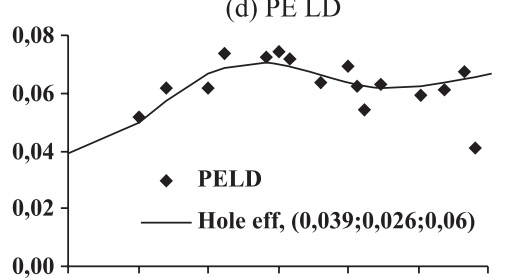

(f) PE LC

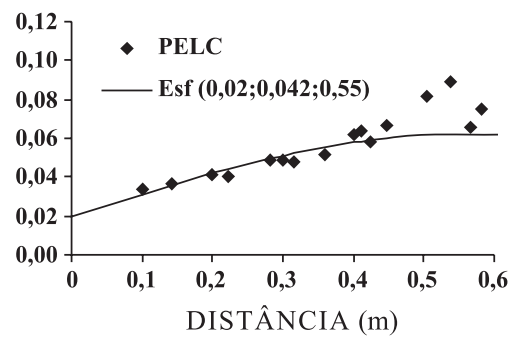

Figura 2. Semivariogramas da resistência à penetração (RP) e da resistência do solo à infiltração da água (PE) nos três perfis dos solos Latossolo Vermelho eutroférrico em plantio direto (LD), Nitossolo Vermelho distroférrico em plantio direto (ND) e Latossolo Vermelho eutroférrico em preparo convencional (LC). 


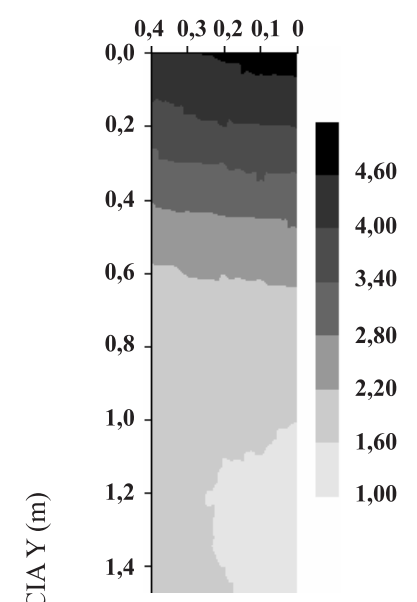

(a) RP LD

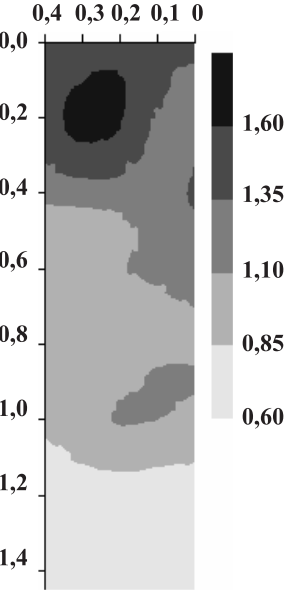

(d) PE LD

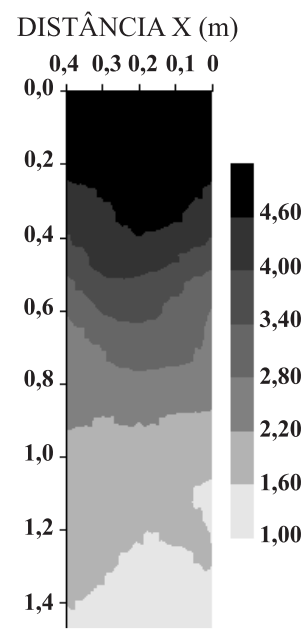

(b) RP ND

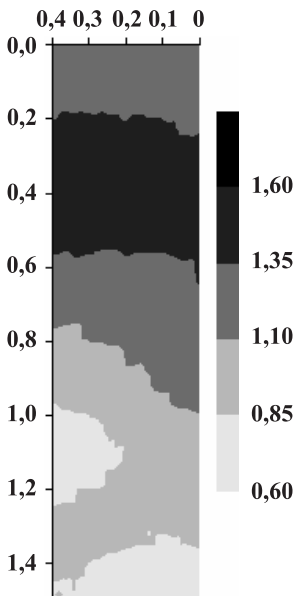

(e) PE ND

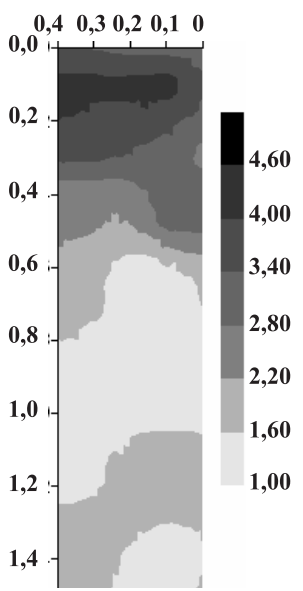

(c) RP LC

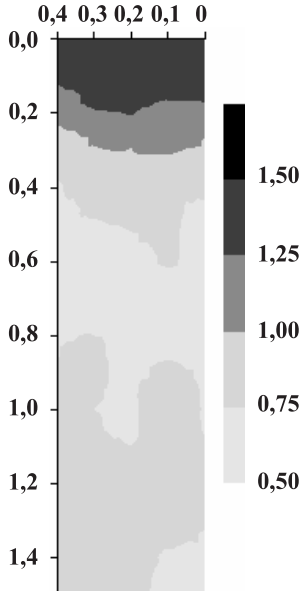

(f) PE LC

Figura 3. Mapas da resistência à penetração $(\mathrm{RP}), \mathrm{em} \mathrm{kg} \mathrm{cm}^{-2}$, e da resistência do solo à infiltração da água (PE), em kg cm${ }^{-2}$, nos três perfis dos solos Latossolo Vermelho eutroférrico em plantio direto (LD), Nitossolo Vermelho distroférrico em plantio direto (ND) e Latossolo Vermelho eutroférrico em preparo convencional (LC).

também que o solo sob cultivo convencional já se encontrava em pousio por três meses na época das avaliações e a grade de medição nos solos sob plantio direto foi posicionada abrangendo a linha e entrelinha das plantas de triticale (0,0 a 0,40 m), que foi semeado no espaçamento de 0,20 m entre linhas.

O efeito entendido como pedogenético na variabilidade espacial da resistência à penetração na parede do perfil dá-se pela maior resistência no Nitossolo (ND) que nos Latossolos (LD e LC), encontrado em toda profundidade medida $(\sim 1,4 \mathrm{~m})$ do perfil. Contudo, esse efeito é mais pronunciado até 1,0 m, onde ocorrem propriedades níticas nesse perfil. Essa é certamente uma consequência da maior coesividade do perfil do Nitossolo, decorrente de sua estruturação.

Em relação à variabilidade espacial da resistência do solo à infiltração da água, medida na parede do perfil, ambos os efeitos, de manejo e pedogenético, podem ser observados. Primeiramente, a permeabilidade medida parece indicar que o sistema PD proporciona maior permeabilidade ao solo que o cultivo convencional. Justifica-se esse resultado pelo fato de o sistema PD permitir maior continuidade de poros, devido ao seu não revolvimento. O efeito pedogenético observado é a maior permeabilidade no Nitossolo (ND) - fato justificado ainda pelo forte grau de desenvolvimento da estrutura, que proporciona maior porosidade no contato entre as unidades estruturais, facilitando a condução da água.

Deve-se ressaltar também que, para o Nitossolo, as separações de horizontes com base na morfologia do solo no campo equivalem às separações produzidas pelas medições das propriedades físicas feitas na parede do perfil, em que interpolações foram feitas por meio da geoestatística. Isso é mais nítido para a medida de resistência à penetração na profundidade que separa o horizonte Ap do Bt $(0,27 \mathrm{~m})$, descrita em campo como 
transição abrupta e ondulada (0,20-0,34 m). Essa estreita associação comprova a validade da descrição morfológica realizada em campo como representativa de resultados físicos quantificáveis do solo.

\section{CONCLUSÕES}

1. O manejo não afetou a diferenciação de horizontes dos Latossolos estudados, à exceção do aumento da profundidade do horizonte A no sistema plantio direto, em consequência do aumento do teor de matéria orgânica, o que alterou a classificação desse horizonte de A moderado para A proeminente.

2. Os limites verticais dos horizontes diagnósticos de superfície e subsuperfície definidos por critérios morfológicos, como estrutura e consistência, mostraram estreita associação com as propriedades físicas mensuradas, validando os critérios morfológicos na separação de camadas de solo com propriedades físicas diferenciadas.

3. A mensuração das propriedades físico-hídricas dos solos resistência à infiltração de água, retenção de água e resistência à penetração diferenciaram os horizontes diagnósticos $\mathrm{B}$ latossólicos do $\mathrm{B}$ nítico. Isso valida os critérios taxonômicos para discriminação desses horizontes nos solos estudados e consolida o uso desses critérios morfológicos e taxonômicos como indicadores de propriedades físicas diferenciadas entre Latossolos e Nitossolos.

4. A dependência espacial encontrada para a resistência à infiltração de água e à penetração, por meio da análise geoestatística, é compatível e complementar à descrição morfológica e às demais propriedades físicas mensuradas nos perfis do solo.

\section{LITERATURA CITADA}

CAMARGO, O.A.; MONIZ, A.C.; JORGE, J.A. \& VALADARES, J.M.A.S. Métodos de análise química, mineralógica e física de solos do Instituto Agronômico de Campinas. Campinas, Instituto Agronômico de Campinas, 1986. 94p. (IAC, Boletim Técnico, 106)

COOPER, M. \& VIDAL-TORRADO, P. Caracterização morfológica, micromorfológica e físico-hídrica de solos com horizonte B nítico. R. Bras. Ci. Solo, 29:581-595, 2005.

CRUZ, A.C.R.; PAULETTO, E.A.; FLORES, C.A. \& SILVA, J.B. Atributos físicos e carbono orgânico de um Argissolo Vermelho sob sistemas de manejo. R. Bras. Ci. Solo, 27:1105-1112, 2003.

FERREIRA, M.M.; FERNANDES, B. \& CURI, N. Influência da mineralogia da fração argila nas propriedades físicas de Latossolos da região sudeste do Brasil. R. Bras. Ci. Solo, 23:515-524, 1997.
GOLDEN SOFTWARE. Surfer 7.0. Contouring and 3D surface mapping for scientist's engineers. User's Guide. New York, Golden Software, 1999. 619p.

GOOVAERTS, P. Geostatistics for natural resources evaluation. New York, Oxford University Press, 1997. 483p.

GREGO, C.R.;VIEIRA, S.R.; ANTONIO, A.M.; DELLA ROSA, S.C. \& TISSELLI, A.C.P.C. Análise da variabilidade do teor de água e permeabilidade de um Latossolo Vermelho eutroférrico em Campinas. In: CONGRESSO BRASILEIRO DE AGRICULTURA DE PRECISÃO, 2004. Anais... Piracicaba, Fundação de Estudos Agrários Luiz de Queiroz, 2004. CD ROM

ISAAKS, E.H. \& SRIVASTAVA, R.M. An introduction to applied geostatistics. New York, Oxford University Press, 1989. $561 \mathrm{p}$.

JORGE, J.A. \& PRADO, H. Porosidade, consistência e propriedades hídricas de três Podzólicos Vermelhoamarelos e uma Terra Roxa Estruturada. R. Bras. Ci. Solo, 12:1-6, 1988.

KLUTE, A. Water retention: Laboratory methods. In: BLACK, C.A., ed. Methods of soil analysis. I. Physical and mineralogical methods. Madison, American Society of Agronomy/Soil Science Society of America, 1986. p.635662.

LEMOS, R.C. \& SANTOS, R.D. Manual de descrição e coleta de solo no campo. 3.ed. Campinas, Sociedade Brasileira de Ciência do Solo, 1996. 84p.

LIMA, H.V.; SILVA, A.P.; JACOMINE, P.T.K.; ROMERO, R.E. \& LIBARDI, P.L. Identificação e caracterização de solos coesos no estado do Ceará. R. Bras. Ci. Solo, 28:467-476, 2004.

MARQUES JR, J.; SOUZA, Z.M.; PEREIRA, G.T. \& BARBIERI, D.M. Variabilidade espacial de matéria orgânica, $\mathrm{P}, \mathrm{K}$ e CTC de um Latossolo cultivado. R. Biol. Ci. Terra, 8:143152,2008 .

SANTOS, H.G.; JACOMINE, P.K.T.; ANJOS, L.H.C.; OLIVEIRA, V.A.; OLIVEIRA, J.B.; COELHO, M.R.; LUMBRERAS, J.F. \& CUNHA, T.J.F. Sistema brasileiro de classificação de solos. 2.ed. Rio de Janeiro, 2006. 306p.

SILVA, H.J.N. \& RIBEIRO, M.R. Caracterização de Latossolo Amarelo sob cultivo contínuo de cana-de-açúcar no estado de Alagoas: Atributos morfológicos e físicos. R. Bras. Ci. Solo, 21:677-684, 1997.

SILVA, V.R.; REINERT, D.J. \& REICHERT, J.M. Resistência mecânica do solo à penetração influenciada pelo tráfego de uma colhedora em dois sistemas de manejo do solo. Ci. Rural, 30:795-801, 2000.

SOIL SURVEY STAFF. Soil taxononmy - A basic system of soil classification for making and interpreting soil survey. 2.ed. Washington, United States Department of Agriculture, 1999. 871p.

SOUZA, Z.M.; MARQUES JUNIOR, J. \& PEREIRA, G.T. Otimização amostral de atributos de Latossolos considerando aspectos solo-relevo. Ci. Rural, 36:829-836, 2006. 
van GENUCHTEN, M.T. A closed-form equation for predicting the hydraulic conductivity of unsaturated soils. Soil Sci. Soc. Am. J., 44:892-898, 1980.

VIEIRA, S.R.; MILLETE, J.A.; TOPP, G.C. \& REYNOLDS, W.D. Handbook for geostatistical analysis of variability in soil and meteorological parameters. In: ALVAREZ V., V.H.; SCHAEFER, C.E.G.R.; BARROS, N.F.; MELLO, W.V. \& COSTA, L.M., eds. Tópicos em ciência do solo. Viçosa, MG, Sociedade Brasileira de Ciência do Solo, 2002. v.2. p.1-45.

VIEIRA, S.R. Geoestatística em estudos de variabilidade espacial do solo. In: NOVAIS, R.F.; ALVAREZ, V.H. \& SCHAEFER, G.R., eds. Tópicos em ciência do solo. Viçosa, MG, Sociedade Brasileira de Ciência do Solo, 2000. v.1. p.1-54.
VIEIRA, S.R.; XAVIER, M.A. \& GREGO, C.R. Aplicações de geoestatística em pesquisa com cana-de-açúcar. In: MIRANDA-DINARDO, L.L.; VASCONCELOS, A.C.M. \& LANDELL, M.G.A., eds. Cana-de-açúcar. Campinas, Instituto Agronômico, 2008. p.839-852.

WARRICK, A.W. \& NIELSEN, D.R. Spatial variability of soil physical properties in the field. In: HILLEL, D., ed. Applications of soil physics. New York, Academic Press, 1980. p.319-344.

ZIMBACK, C.R. Análise especial de atributos químicos de solo para o mapeamento da fertilidade do solo. Botucatu, Universidade Estadual de São Paulo, 2001. 114p. (Tese de Livre Docência) 